\title{
Musa Paradisiaca Extract as a Green Inhibitor for Corrosion of Mild Steel in 0.5 M Sulphuric Acid Solution
}

\author{
Ramananda S. Mayanglambam, ${ }^{* 1}$ Vivek Sharma, ${ }^{1}$ Gurmeet Singh $^{2}$ \\ ${ }^{I}$ Department of Chemistry, Kirorimal College, University of Delhi, India \\ ${ }^{2}$ Department of Chemistry, University of Delhi, Delhi-110007, India
}

Received 19 February 2011; accepted 22 December 2011

\begin{abstract}
The effect of extract of Musa paradisiaca on corrosion inhibition of mild steel in aqueous $0.5 \mathrm{M}$ sulphuric acid was investigated by weight loss method, potentiodynamics polarisation technique and electrochemical impedance spectroscopy (EIS). The inhibition efficiency is found to increase with increase in concentration of the extract. Polarization measurement indicates that Musa paradisiaca acts as a mixedtype inhibitor and the inhibition efficiency decreases with rise in temperature. The inhibition is assumed to occur via adsorption of inhibitor molecules on metal surface, which obeys Langmuir adsorption isotherm. The activation energy $\left(E_{a}\right)$ and other thermodynamic parameters for inhibition process were calculated. These thermodynamic parameters indicate a strong interaction between the inhibitor and the mild steel surface. SEM and AFM studies confirmed the adsorption of inhibitor molecules on mild steel surface.
\end{abstract}

Keywords: acid corrosion; EIS; SEM; corrosion inhibition.

\section{Introduction}

The study of corrosion inhibition using inhibitor in acidic media is one of the most challenging areas in the current research, due to its potential applications in industries such as acid pickling, industrial cleaning, acid descaling, oil-well acid in oil recovery and petrochemical processes [1-5]. The ability of a compound to serve as inhibitor is dependent on its ability to form a compact barrier film and/or nature of adsorption on metal surface. The majority of well-known inhibitors are organic compounds containing heteroatoms, such as $\mathrm{O}, \mathrm{N}, \mathrm{S}$ and multiple bonds [6]. Although many synthetic compounds show good anticorrosive properties, most of them are highly toxic to both human beings and environments [7]. The

\footnotetext{
* Corresponding author. E-mail address: ramananda2002@yahoo.co.in
} 
known hazardous effect of most synthetic organic inhibitors and restrictive environmental regulations have now made researchers to focus on the need to develop cheap, non-toxic and environmental friendly inhibitors like natural products. The natural product extracts are viewed as an incredibly rich source of naturally synthesized chemical compounds that can be extracted by simple procedures with low cost, and are biodegradable in nature [8]. This area of research is of much importance because in addition to being environmentally friendly and ecologically acceptable, plant products are inexpensive, readily available and renewable source of materials [9]. The use of these natural products, such as extracted compounds from the leaves, flowers, seeds and roots, as corrosion inhibitors have been widely reported by several authors. M.G. Sethuraman et al. [10] studied the corrosion inhibitive effect of the extract of black pepper on mild steel in $1 \mathrm{M} \mathrm{H}_{2} \mathrm{~S}_{4}$ media, P.C. Okafor [11] studied the inhibitive action of leaves, seeds and a combination of leaves and seeds extracts of phyllanthus amarus on mild steel corrosion in $\mathrm{HCl}$ and $\mathrm{H}_{2} \mathrm{SO}_{4}$ solutions, A.M.Abdel-Gaber et al. [12] studied the inhibitive effect of lupine (lupinous albus L.) extract on the corrosion of steel in aqueous solution of $1 \mathrm{M} \mathrm{H}_{2} \mathrm{SO}_{4}$ and $2 \mathrm{M} \mathrm{HCl}, \mathrm{K} . \mathrm{O}$. Orubite et al. [13] studied the inhibition of the corrosion of mild steel in $\mathrm{HCl}$ solutions by extract of the leaves of Nypa fruticans Wurmb, N.O.Eddy et al. [14] studied the inhibitive and adsorption properties of ethanol extract of verninia amygdalina for the corrosion of mild steel.

This study aims to gain some insight into the corrosion of mild steel in $0.5 \mathrm{H}_{2} \mathrm{SO}_{4}$ in the presence of Musa paradisiaca plant extract as a corrosion inhibitor. The aqueous extract of leaves and flowers of Musa paradisiaca plant in $0.5 \mathrm{M}$ sulphuric acid was tested by weight loss, potentiodynamic polarization and electrochemical impedance techniques. SEM and AFM studies were also used to study the surface morphologies. Musa paradisiaca is a perennial tree like herb, which is commonly known as banana and is widely found in northern India. The stem juices of Musa paradisiaca have been reported to be used in the treatment of nervous affections like epilepsy, hysteria and in dysentery and diarrhea [15]. Banana is a good source of vitamins A, B and C and it also has a high content of carbohydrates like fructose, xylose, galactose, glucose and mannose. However, literature search reveals that no study has been done on the inhibitive effects of Musa paradisiaca extract on acidic corrosion of mild steel.

\section{Material and methods}

\section{Preparation of extract of Musa paradisiaca}

Double distilled water and analytical reagents-grade $\mathrm{H}_{2} \mathrm{SO}_{4}$ (Qualingens, 98.0\%) were used for preparing solutions. The leaves of Musa paradisiaca were dried for 6 hours in an oven at $70{ }^{\circ} \mathrm{C}$ and ground into powder and 10 grams of the powder of Musa paradisiaca were refluxed in $100 \mathrm{~mL}$ double distilled water for 1 hour. The extract of the plant was prepared by evaporating the filtrate. The required concentrations of solution were prepared by using solid paste residue obtained on evaporation of the filtrate in aqueous solution of $0.5 \mathrm{M} \mathrm{H}_{2} \mathrm{SO}_{4}$. 


\section{Weight loss method}

Mild steel specimens having percent composition of $\mathrm{C}(0.18), \mathrm{Si}(0.19)$, Mn (0.51), P (0.044), S (0.057), Cr (0.14), Ni (0.09), Mo (0.02), Cu (0.06), V (less than 0.01) and remaining $\mathrm{Fe}$ (chemical analysis: \% by weight by equipment, IS:228 \&ICP-OES) were used. Rectangular specimens with dimension 1 x 4 x 1 $\mathrm{cm}$ were used in weight loss experiments. The specimens were polished successively using emery papers of 150, 180, 320, 400, 600 and 1000 grade. The polished surface were degreased with acetone and washed with distilled water before the experiment. Weight loss of mild steel coupons immersed in $100 \mathrm{~mL}$ of the electrolyte with and without the extract was determined after 4 hours at 298 $\mathrm{K}$. The percentage inhibition efficiency (I\%) was calculated from the following equation[16]:

$$
I \%=\frac{W_{0}-W_{i}}{W_{0}} \times 100
$$

where $\mathrm{W}_{0}$ and $\mathrm{W}_{\mathrm{i}}$ are weight losses of mild steel in absence and presence of the extract.

\section{Electrochemical measurements}

An electrochemical cell assembly of three electrodes was used for potentiodynamic polarization and electrochemical impedance measurements, in which the working electrode was mild steel, a saturated Calomel electrode (SCE) was the reference electrode, and a platinum wire was the counter electrode. The working electrode was coated thoroughly with epoxy resin keeping surface area of $1 \mathrm{~cm}^{2}$ for the study. The surface of the mild steel was abraded into uniform surface with 150, 320, 400, 600 grade emery papers and finally polished by 1000 grade emery papers. The polished surfaces were degreased with acetone and washed with distilled water before the experiment. The measurements were done by using computer controlled electrochemical workstation of $\mathrm{CHI} 760 \mathrm{c}$ model. Before each polarization and EIS measurement, the working electrode was introduced into the test solution and kept for 4 hours to attain the open circuit potential (OCP). Polarization measurements were made under thermostatic conditions at $298 \mathrm{~K}, 308 \mathrm{~K}, 318 \mathrm{~K}$ and $328 \mathrm{~K}$, and the measurements were carried out in the range of potential from -1.2 to $2 \mathrm{~V}$ with scan rate of $0.01(\mathrm{~V} / \mathrm{s})$ and quiet time of 2 seconds. The percentage inhibition efficiency (I\%) from the polarization measurement was calculated using the following equation [17]:

$$
I \%=\frac{i_{\text {corr }}^{0}-i_{\text {corr }}^{i}}{i_{\text {corr }}^{0}} \times 100
$$

where $i_{\text {corr }}^{\mathrm{o}}$ and $\mathrm{i}_{\text {corr }}^{\mathrm{i}}$ are the corrosion current density values without and with inhibitor, respectively.

Electrochemical impedance measurements were carried out at $298 \mathrm{~K}$ and the measurement of the response of the electrochemical system to a.c. excitation, with a frequency ranging from 100000 to $0.1 \mathrm{~Hz}$ and peak to peak a.c. amplitude of $0.005 \mathrm{~V}$ with quiet time of 2 seconds, was done. The percentage inhibition efficiency (I\%) from the electrochemical impedance measurement was calculated using the following equation [18]: 


$$
I \%=\frac{R_{c t(i)}-R_{c t(a)}}{R_{c t(i)}} \times 100
$$

where $R_{c t(i)}$ and $R_{c t(a)}$ are the values of charge transfer resistance in presence and absence of the inhibitor, respectively.

\section{Surface analysis}

The test coupons of size $1 \times 1 \mathrm{~cm}^{2}$ were exposed in $100 \mathrm{~mL}$ of $0.5 \mathrm{M} \mathrm{H}_{2} \mathrm{SO}_{4}$ solutions in absence and presence of 1 and 3 grams of the plant extracts for 5 hours at $298 \mathrm{~K}$, and then washed with distilled water. After drying the specimens, they were examined by scanning electron microscope (SEM) model Leo 435 VP with an Oxford Inca energy dispersion spectrometer system and an atomic force microscope (AFM) model VEECO CP II.

\section{Results and discussions}

\section{Weight loss method}

The percentage of inhibition efficiency (I\%) at different concentrations of Musa paradisiaca extract at $298 \mathrm{~K}$ are summarized in the Table 1 . From the table, it is clear that the inhibition efficiency of the extract on corrosion of mild steel increases with increase in concentration. It increases up to $82.7 \%$ when the concentration of the extract increases up to 3 grams per litre.

Table 1. Corrosion parameters for mild steel in $0.5 \mathrm{M} \mathrm{H}_{2} \mathrm{SO}_{4}$ solution in absence and presence of different Musa paradisiaca extract concentrations.

\begin{tabular}{cccc}
\hline Temperature (K) & Solution & (Conc.),g/L & $\mathrm{I} \%$ \\
\hline 298 & $0.5 \mathrm{M} \mathrm{H}_{2} \mathrm{SO}_{4}$ & 0.0 & - \\
& & 1.0 & 61.5 \\
& & 2.0 & 70.4 \\
& & 3.0 & 82.7 \\
\hline
\end{tabular}

\section{Potentiodynamic polarization measurement}

Potentiodynamic polarization curves for mild steel in $0.5 \mathrm{M} \mathrm{H}_{2} \mathrm{SO}_{4}$ solutions in absence and presence of various concentrations of Musa paradisiaca extract at $298 \mathrm{~K}$ are shown in Fig. 1. The extrapolation of Tafel straight line allows the calculation of the corrosion current density $\left(i_{\text {corr }}\right)$. The values of $i_{\text {corr }}$, corrosion potential $\left(\mathrm{E}_{\mathrm{corr}}\right)$, cathodic and anodic Tafel slopes $\left(\beta_{\mathrm{c}}\right.$ and $\left.\beta_{\mathrm{a}}\right)$ and percentage of inhibition efficiency (I\%), are given in the Table 2.

At a given temperature, the addition of the extract of Musa paradisiaca to the acid solution increases both the anodic and cathodic overpotentials and decreases the corrosion current density $\left(i_{\text {corr }}\right)$. The change in cathodic and anodic Tafel slopes $\left(\beta_{\mathrm{c}}\right.$ and $\left.\beta_{\mathrm{a}}\right)$ shown in Table 2 indicates that adsorption of Musa paradisiaca extract modifies the mechanism of the anodic dissolution as well as cathodic hydrogen evolution. From Fig. 1, it is clear that both cathodic and anodic reactions are inhibited, and the inhibition increases as the inhibitor concentration increases in acid media. From Table 2, it is clear that there is no 
definite trend in the shift of $\mathrm{E}_{\text {corr }}$ values, in presence of various concentrations of Musa paradisiaca extract in $0.5 \mathrm{M} \mathrm{H}_{2} \mathrm{SO}_{4}$ solutions. This result indicates that Musa paradisiaca extract can be classified as a mixed type of inhibitor in $0.5 \mathrm{M}$ $\mathrm{H}_{2} \mathrm{SO}_{4}$ solutions [19].

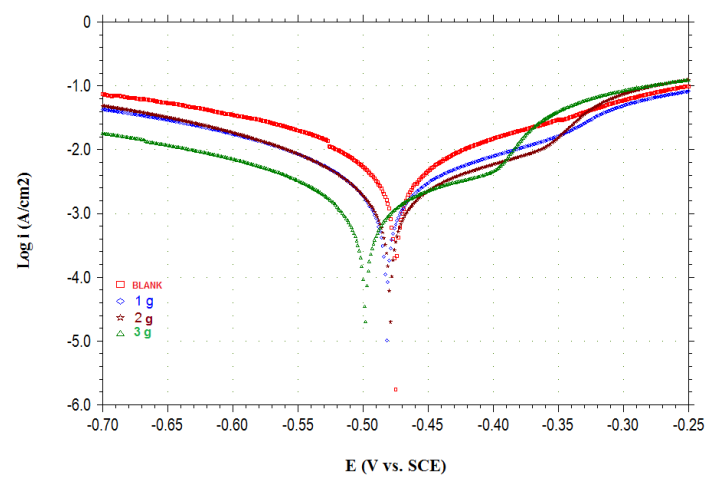

Figure 1. Potentiodynamic polarization curves for mild steel in $0.5 \mathrm{M} \mathrm{H}_{2} \mathrm{SO}_{4}$ solution in absence $_{\text {and }}$ presence of different concentrations of Musa paradisiaca extract at $298 \mathrm{~K}$.

A detailed study of steady state potentiostatic behavior of the anodic dissolution of mild steel in $0.5 \mathrm{M} \mathrm{H}_{2} \mathrm{SO}_{4}$ in the absence and presence of various concentrations of the extract of Musa paradisiaca plant has been carried out in terms of the electrochemical parameters, e.g., critical current density $\left(i_{c}\right)$, Flade potential $\left(\mathrm{E}_{\mathrm{pp}}\right)$ and passive current density $\left(\mathrm{i}_{\mathrm{p}}\right)$. The critical current density $\left(\mathrm{i}_{\mathrm{c}}\right)$ of $0.5 \mathrm{M} \mathrm{H}_{2} \mathrm{SO}_{4}$ is found to be $363 \mathrm{~m} \mathrm{~A} \mathrm{~cm}^{-2}$, which is considerably higher than that of the solution having the extracts of the plant. The values of critical current density $\left(i_{c}\right)$ in the presence of the extracts are found to decrease from $308 \mathrm{~m} \mathrm{~A}$ $\mathrm{cm}^{-2}$ to $134 \mathrm{~m} \mathrm{~A} \mathrm{~cm}^{-2}$ on increasing in concentration from $1 \mathrm{~g}$ to $3 \mathrm{~g}$ of the extracts, and the passive current density $\left(i_{p}\right)$ values also significantly lower from $73 \mathrm{~m} \mathrm{~A} \mathrm{~cm}^{-2}$ to $24 \mathrm{~m} \mathrm{~A} \mathrm{~cm}^{-2}$ on increasing in concentration of the extract from 1 $\mathrm{g}$ to $3 \mathrm{~g}$, in comparison to $172 \mathrm{~m} \mathrm{~A} \mathrm{~cm}^{-2}$ for $0.5 \mathrm{M} \mathrm{H}_{2} \mathrm{SO}_{4}$. These results indicate that the extract of Musa paradisiaca is a good passivator and it is able to form some kind of protective film on mild steel surface which results in inhibition of metal dissolution.

\section{Effect of temperature}

The effect of temperature on the inhibition efficiency is summarized in the Table 2. It shows that an increase in temperature decreases the inhibition efficiency. This can be explained on the fact that an increase in temperature usually accelerates corrosive processes, particularly in media in which $\mathrm{H}_{2}$ gas evolution accompanies corrosion, giving rise to higher dissolution rates of the metal. The activation energies $\left(E_{a}\right)$ for the corrosion process in absence and presence of the inhibitor are evaluated from Arrhenius equation [20]:

$$
\mathrm{k}=\mathrm{A} \mathrm{e}^{(-\mathrm{E} a / \mathrm{RT})}
$$

where $\mathrm{A}$ is the pre-exponential factor, $\mathrm{T}$ is absolute temperature, $\mathrm{R}$ is the gas constant and $\mathrm{k}$ is the rate constant of metal dissolution reaction which is directly 
related to corrosion current density. Therefore, the equation can be rewritten as [21]:

$$
\mathrm{i}_{\text {corr }}=\mathrm{A} \mathrm{e}^{(-\mathrm{Ea} / \mathrm{RT})}
$$

where $\mathrm{i}_{\text {corr }}$ is the corrosion current density. The activation energies of corrosion reaction in presence and absence of the inhibitor are determined by plotting log $\mathrm{i}_{\text {corr }}$ against $1 / \mathrm{T}$, as shown in Fig. 2 . The values of the activation energies are given in Table 3.

Table 2. Electrochemical parameters for mild steel corrosion in $0.5 \mathrm{M} \mathrm{H}_{2} \mathrm{SO}_{4}$ solution in absence and presence of different Musa paradisiaca extract concentrations.

\begin{tabular}{|c|c|c|c|c|c|c|c|c|}
\hline Temperature (K) & Solution & (Conc.), $\mathrm{g} / \mathrm{L}$ & $-\mathrm{E}_{\mathrm{cor}}(\mathrm{mV}$ vs.SCE$)$ & $\beta_{\mathrm{c}}(\mathrm{mV} / \mathrm{Dec})$ & $\beta_{\mathrm{a}}(\mathrm{mV} / \mathrm{Dec})$ & $\mathrm{i}_{\text {corr }}\left(\mathrm{mA} / \mathrm{cm}^{2}\right)$ & $\mathrm{I} \%$ & $\theta$ \\
\hline \multirow[t]{4}{*}{298} & $0.5 \mathrm{M} \mathrm{H}_{2} \mathrm{SO}_{4}$ & 0.0 & 475 & 54 & 61 & 8.11 & - & - \\
\hline & & 1.0 & 482 & 64 & 62 & 3.48 & 60.5 & 0.605 \\
\hline & & 2.0 & 479 & 70 & 63 & 2.79 & 68.3 & 0.683 \\
\hline & & 3.0 & 498 & 58 & 103 & 1.46 & 81.9 & 0.819 \\
\hline \multirow[t]{4}{*}{308} & $0.5 \mathrm{M} \mathrm{H}_{2} \mathrm{SO}_{4}$ & 0.0 & 475 & 53 & 59 & 14.99 & - & - \\
\hline & & 1.0 & 478 & 60 & 61 & 7.47 & 50.2 & 0.502 \\
\hline & & 2.0 & 492 & 61 & 61 & 5.74 & 61.7 & 0.617 \\
\hline & & 3.0 & 479 & 73 & 81 & 3.68 & 75.5 & 0.755 \\
\hline \multirow[t]{4}{*}{318} & $0.5 \mathrm{M} \mathrm{H}_{2} \mathrm{SO}_{4}$ & 0.0 & 481 & 48 & 51 & 16.39 & - & - \\
\hline & & 1.0 & 513 & 54 & 45 & 9.75 & 40.5 & 0.405 \\
\hline & & 2.0 & 501 & 56 & 51 & 7.10 & 56.6 & 0.566 \\
\hline & & 3.0 & 488 & 62 & 62 & 5.20 & 68.3 & 0.683 \\
\hline \multirow[t]{4}{*}{328} & $0.5 \mathrm{M} \mathrm{H}_{2} \mathrm{SO}_{4}$ & 0.0 & 500 & 49 & 50 & 19.98 & - & - \\
\hline & & 1.0 & 475 & 63 & 62 & 13.85 & 30.6 & 0.306 \\
\hline & & 2.0 & 480 & 54 & 46 & 10.52 & 47.3 & 0.473 \\
\hline & & 3.0 & 478 & 58 & 64 & 8.44 & 57.8 & 0.578 \\
\hline
\end{tabular}

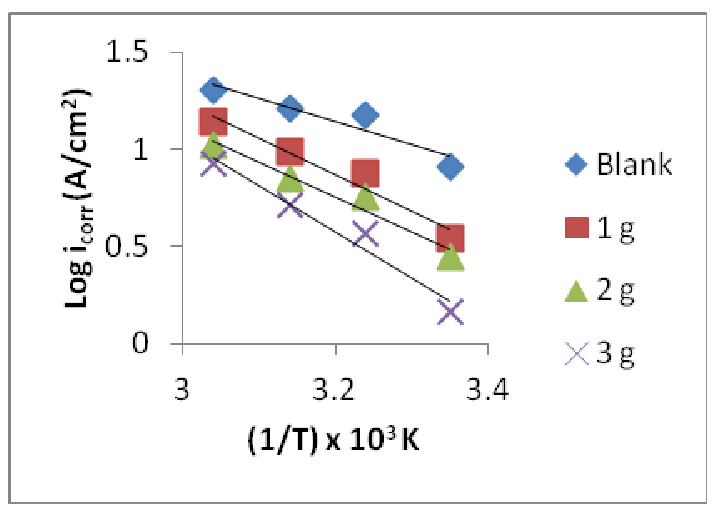

Figure 2. Arrhenius plots of $\log \mathrm{i}_{\text {corr }}$ versus $1 / \mathrm{T}$ for mild steel corrosion in $0.5 \mathrm{M} \mathrm{H}_{2} \mathrm{SO}_{4}$ solution in absence and presence of different concentrations of Musa paradisiaca extract.

The values of activation energies $\left(\mathrm{E}_{\mathrm{a}}\right)$ increased in presence of the extract at all the studied concentrations in $0.5 \mathrm{M} \mathrm{H}_{2} \mathrm{SO}_{4}$, which suggested that the adsorbed organic matters create a physical barrier to charge and mass transfer leading to reduction in corrosion rate [21]. 
Table 3. Calculated values of activation energy $\left(\mathrm{E}_{\mathrm{a}}\right)$ for various concentrations of Musa paradisiaca extract during mild steel corrosion in $0.5 \mathrm{M} \mathrm{H}_{2} \mathrm{SO}_{4}$ solution.

\begin{tabular}{|c|c|c|c|}
\hline Solution & Concentration $(\mathrm{g} / \mathrm{L})$ & $\mathrm{E}_{\mathrm{a}}(\mathrm{k} \mathrm{J} / \mathrm{mol})$ & $\mathrm{R}^{2}$ \\
\hline $0.5 \mathrm{H}_{2} \mathrm{SO}_{4}$ & $\begin{array}{l}0.0 \\
1.0 \\
2.0 \\
3.0\end{array}$ & $\begin{array}{l}22.72 \\
33.99 \\
35.72 \\
45.47\end{array}$ & $\begin{array}{c}0.876 \\
0.955 \\
0.952 \\
0.963\end{array}$ \\
\hline
\end{tabular}

\section{Adsorption isotherms}

Two main types of the interaction often describe adsorption of organic inhibitors on a corroding metal surface viz: chemical adsorption and physical adsorption. It has been suggested that physisorbed molecules are attached to the metal at local cathodes and essentially retard metal dissolution by stifling the cathodic reaction, whereas chemisorbed molecules protect anodic areas and reduce the inherent reactivity of the metal at the sites where they are attached. The more efficient inhibitors appear to protect anodic areas preferentially by chemisorption.

Basic information on the interaction between the inhibitor and mild steel surface can be provided by the adsorption isotherms. For this purpose, the values of surface coverage $(\theta)$ at different concentrations of Musa paradisiaca extract in acid media in the temperature range from $298 \mathrm{~K}$ to $328 \mathrm{~K}$ have been calculated to explain the best isotherm to determine the adsorption process. The value of the surface coverage $(\theta)$ was calculated using the relationship [22]:

$$
\theta=[\mathrm{I} \%] / 100
$$

Attempts were made to fit these $\theta$ values to various isotherms including Langmuir, Temkin, Frumkin, El-Awady, Freundlich, and Flory-Huggins, etc.

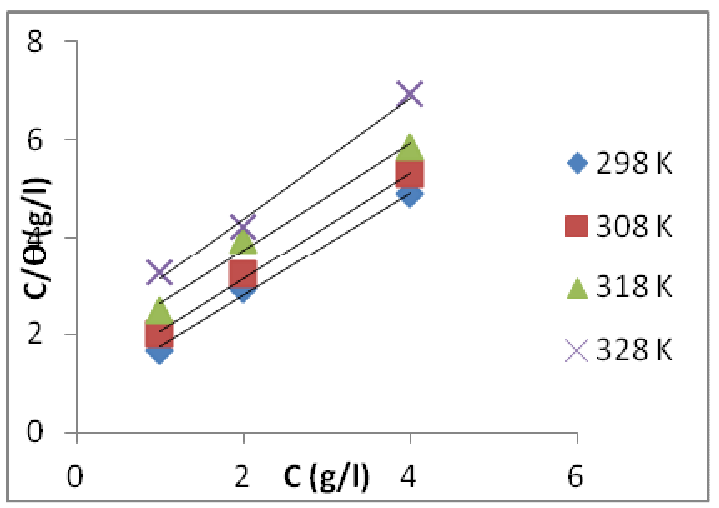

Figure 3. Langmuir adsorption isotherm for the adsorption of Musa paradisiaca extract in $0.5 \mathrm{M} \mathrm{H}_{2} \mathrm{SO}_{4}$ on the surface of mild steel.

The best fit was obtained with Langmuir isotherm as suggested by the plot between $C / \theta$ and $C$ (as shown in Fig. 3) and the linear correlation coefficient of 
the fitted data was close to 1, indicating that the adsorption of the inhibitor molecules obeys the Langmuir adsorption isotherm [23-24]:

$$
[\mathrm{C} / \theta]=\mathrm{C}+\left[1 / \mathrm{K}_{\mathrm{ads}}\right]
$$

where $\mathrm{C}$ is the inhibitor concentration and $\mathrm{K}_{\mathrm{ads}}$ is the equilibrium constant for adsorption/desorption process of the inhibitor molecules on the metal surface. $\mathrm{K}_{\mathrm{ads}}$ values were calculated from the intercept of the plot for adsorption process. The adsorption equilibrium constant, $\mathrm{K}_{\mathrm{ads}}$, is related to the standard free energy $\left(\Delta \mathrm{G}^{\mathrm{o}}{ }_{\mathrm{ads}}\right)$ by the following equation [25]:

$$
\mathrm{K}_{\mathrm{ads}}=[1 / 55] \exp \left[-\Delta \mathrm{G}_{\mathrm{ads}}^{\mathrm{o}} / \mathrm{RT}\right]
$$

The plotting of $\log \mathrm{K}_{\mathrm{ads}}$ against $1 / \mathrm{T}$ (as shown in Fig. 4) gives the value of the standard free energy $\left(\Delta \mathrm{G}_{\text {ads }}^{\mathrm{o}}\right)$ which is equal to $-29.05 \mathrm{~kJ} / \mathrm{mol}$. The negative values of $\Delta \mathrm{G}_{\text {ads }}^{\mathrm{o}}$ ensure the spontaneity of the adsorption process and the stability of the adsorbed layer on the mild steel surface. It is well known that values of $\Delta \mathrm{G}_{\text {ads }}^{\mathrm{O}}$ of the order of $-20 \mathrm{~kJ} / \mathrm{mol}$ or lower are consistent with the electrostatic interaction between organic molecules and metal surface, indicating a physisorption, and the values around - $40 \mathrm{~kJ} / \mathrm{mol}$ or higher involve charge sharing to transfer from the organic molecules to the metal surface to form a coordinate type of bond, indicating a chemisorption [26]. Since calculated value of $\Delta \mathrm{G}^{\mathrm{o}}{ }_{\text {ads }}$ is $29.05 \mathrm{~kJ} / \mathrm{mol}$ which is between the values of physical adsorption and chemical adsorption, it probably meant that both physical and chemical adsorption would take place in process of adsorption [26-27].

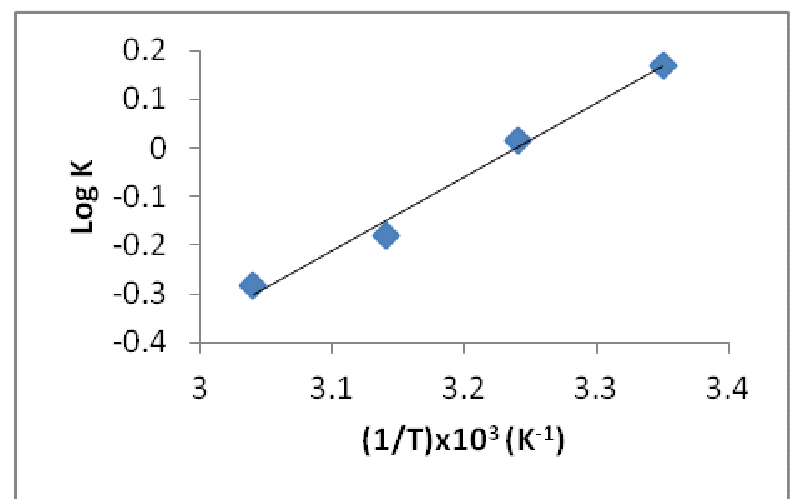

Figure 4. Plots of $\log \mathrm{K}_{\mathrm{ads}}$ against $1 / \mathrm{T}$ for mild steel in $0.5 \mathrm{M} \mathrm{H}_{2} \mathrm{SO}_{4}$ in absence and presence of different concentrations of Musa paradisiaca extract.

By using the transition state equation [28]:

$$
\log \left(\mathrm{i}_{\text {corr }} / \mathrm{T}\right)=\log (\mathrm{R} / \mathrm{Nh})+\Delta \mathrm{S}_{\text {ads }}^{\mathrm{o}} / 2.303 \mathrm{R}-\Delta \mathrm{H}_{\text {ads }}^{\mathrm{o}} / 2.303 \mathrm{RT}
$$

where $\mathrm{N}$ is the Avogadro's number and $\mathrm{h}$ is the Plank's constant, a plot of log $\left(\mathrm{i}_{\text {corr }} / \mathrm{T}\right)$ against $1 / \mathrm{T}$ gives a straight line, as shown in Fig. 5 , and the standard enthalpy change $\Delta \mathrm{H}^{\mathrm{o}}$ ads is evaluated from the slope and the mean value of standard enthalpy change $\left(\Delta \mathrm{H}^{\mathrm{o}}\right.$ ads $)$ is found to be $-35.99 \mathrm{~kJ} / \mathrm{mol}$. The standard adsorption entropy $\left(\Delta \mathrm{S}^{\mathrm{o}}\right.$ ads $)$ is calculated by using the following equation [29]:

$$
\Delta \mathrm{G}_{\text {ads }}^{\mathrm{o}}=\Delta \mathrm{H}_{\mathrm{ads}}^{\mathrm{o}}-\mathrm{T} \Delta \mathrm{S}_{\text {ads }}^{\mathrm{o}}
$$




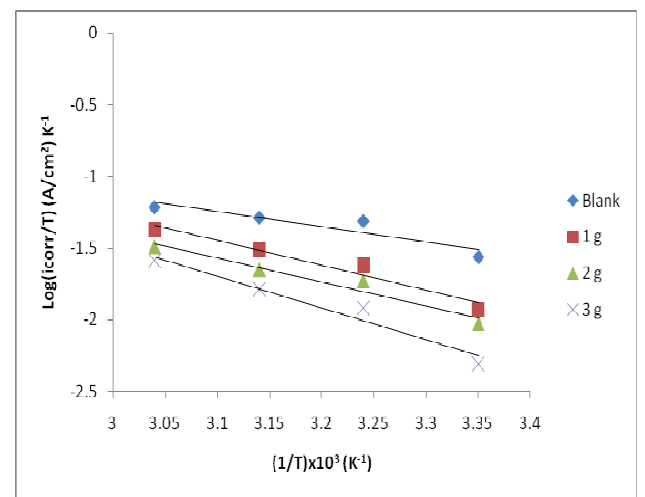

Figure 5. Transition-state plots of $\log \left(\mathrm{i}_{\text {corr }} / \mathrm{T}\right)$ versus $1 / \mathrm{T}$ for mild steel corrosion in 0.5 $\mathrm{M} \mathrm{H}_{2} \mathrm{SO}_{4}$ in absence and presence of different concentrations of Musa paradisiaca extract.

The value of $\Delta \mathrm{S}_{\text {ads }}^{\mathrm{o}}$ is found to be $22.95 \mathrm{Jmol}^{-1} \mathrm{~K}^{-1}$ in presence of Musa paradisiaca in $0.5 \mathrm{M} \mathrm{H}_{2} \mathrm{SO}_{4}$ solution, which is large and positive, meaning that an increase in disordering takes place in going from reactants to the metaladsorbed species reaction complex.

\section{EIS measurements}

EIS technique was applied to investigate the electrode/electrolyte interface and corrosion processes that occur on mild steel surface in presence and absence of Musa paradisiaca extract. To ensure complete characterization of the interface and surface processes, EIS measurements were made at OCP in a wide frequency range at $298 \mathrm{~K}$. Fig. 6 shows Nyquist plots for mild steel electrode immersed in $0.5 \mathrm{M} \mathrm{H}_{2} \mathrm{SO}_{4}$ solution at $298 \mathrm{~K}$ in absence and presence of various concentrations of the extract at the respective open circuit potential. It is clear from Fig. 6 that the diameter of the semicircle increases with the increase in inhibitor concentration in the electrolyte, indicating an increase in corrosion resistance of the material.

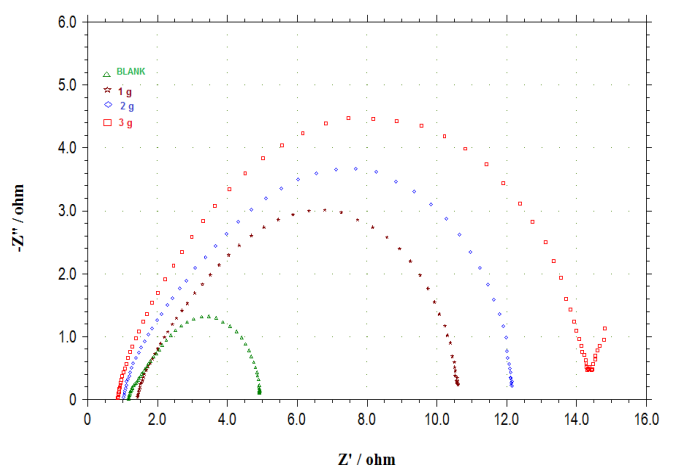

Figure 6. Nyquist plots (EIS) of mild steel immersed in $0.5 \mathrm{M} \mathrm{H}_{2} \mathrm{SO}_{4}$ in absence and presence of different concentrations of Musa paradisiaca extract at $298 \mathrm{~K}$.

The value of electrochemical double layer capacitance $\left(\mathrm{C}_{\mathrm{dl}}\right)$ was calculated at the frequency, $\mathrm{f}_{\max }$ using the following equation [30]: 


$$
\mathrm{C}_{\mathrm{dl}}=1 / 2 \pi \mathrm{f}_{\max } \mathrm{R}_{\mathrm{ct}}
$$

where $f_{\max }$ is the frequency at which the imaginary component of the impedance is maximal.

The impedance data listed in the Table 4 indicate that the values of both $\mathrm{R}_{\mathrm{ct}}$ and $\mathrm{I} \%$ are found to increase by increasing in inhibitor concentration, while the values of $\mathrm{C}_{\mathrm{dl}}$ are found to decrease. This behavior can be attributed to a decrease in the dielectric constant and/ or an increase in the thickness of the electric double layer, suggesting that the inhibitor molecules act by adsorption mechanism at mild steel/acid interface [30].

Table 4. Electrochemical impedance parameters for mild steel corrosion in $0.5 \mathrm{M}$ $\mathrm{H}_{2} \mathrm{SO}_{4}$ solution in absence and presence of different Musa paradisiaca extract concentrations.

\begin{tabular}{cccccc}
\hline Temperature (K) & Solution & (Conc.),g/L & $\mathrm{C}_{\mathrm{dl}}\left(\mathrm{F} \mathrm{cm}^{-2}\right)$ & $\mathrm{R}_{\mathrm{ct}}\left(\Omega \mathrm{cm}^{2}\right)$ & $\mathrm{I} \%$ \\
\hline 298 & $0.5 \mathrm{M} \mathrm{H}_{2} \mathrm{SO}_{4}$ & 0.0 & $105 \times 10^{-3}$ & 4.1 & - \\
& & 1.0 & $34.19 \times 10^{-3}$ & 10.35 & 60.4 \\
& & 2.0 & $23.44 \times 10^{-3}$ & 12.35 & 66.8 \\
& & 3.0 & $16.11 \times 10^{-3}$ & 14.98 & 72.6 \\
\hline
\end{tabular}

\section{Scanning electron microscopy studies}

SEM micrograms of the polished surface of mild steel exposed for 5 hours in 0.5 $\mathrm{M} \mathrm{H}_{2} \mathrm{SO}_{4}$ solutions in absence and presence of 3 grams of Musa paradisiaca extract are shown in Fig. 7 (a)-(b). In the comparison of the SEM micrograms, there were a rough surface on mild steel in absence of the extract and a smooth surface with deposited extract in presence of the extract [31]. This confirms that the extract inhibited corrosion of mild steel through adsorption of the inhibitor molecules on metal surface.

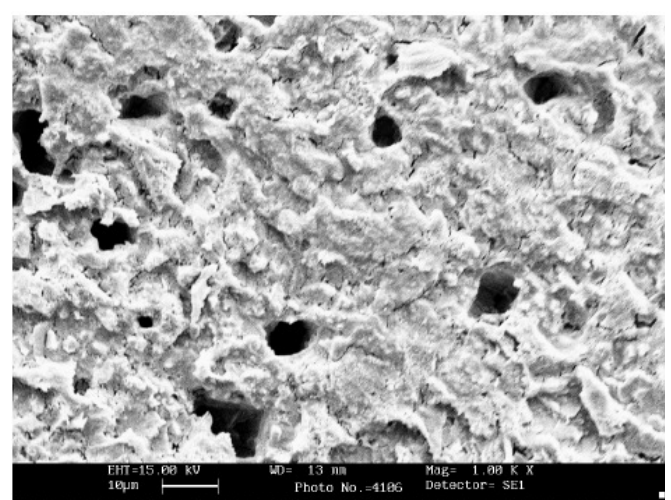

a)

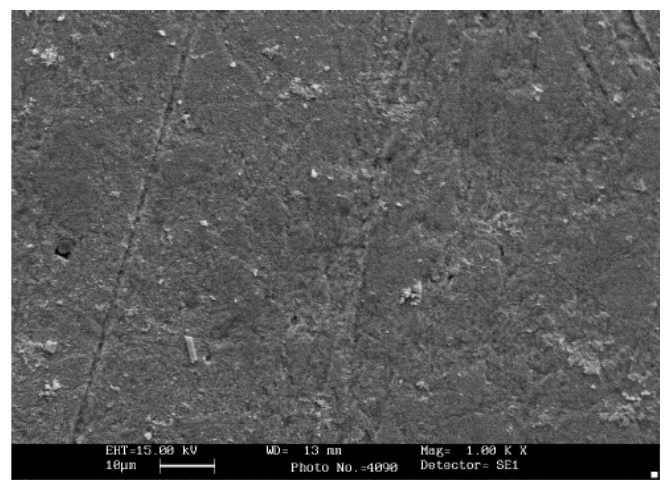

b)

Figure 7. Scanning electron micrograph of polished mild steel after exposure to (a) 0.5 $\mathrm{M} \mathrm{H}_{2} \mathrm{SO}_{4}$, and (b) $0.5 \mathrm{M} \mathrm{H}_{2} \mathrm{SO}_{4}$ containing 3 grams of Musa paradisiaca extract.

\section{Atomic force microscopy (AFM) studies}

AFM images of mild steel exposed for 5 hours in $0.5 \mathrm{M} \mathrm{H}_{2} \mathrm{SO}_{4}$ solutions in absence and presence of 1 gram of extract are shown in Fig. 8 (a)-(b). The roughness of mild steel coupons in $0.5 \mathrm{M} \mathrm{H}_{2} \mathrm{SO}_{4}$ solutions in absence and 
presence of the extract are $152.9 \mathrm{~nm}$ and $56.99 \mathrm{~nm}$, respectively [32]. This indicates that the addition of the extract reduced the surface roughness. AFM images and the roughness quantification are also consistent with SEM studies. This confirms that the corrosion inhibition on mild steel occurs through adsorption of the extract on it.

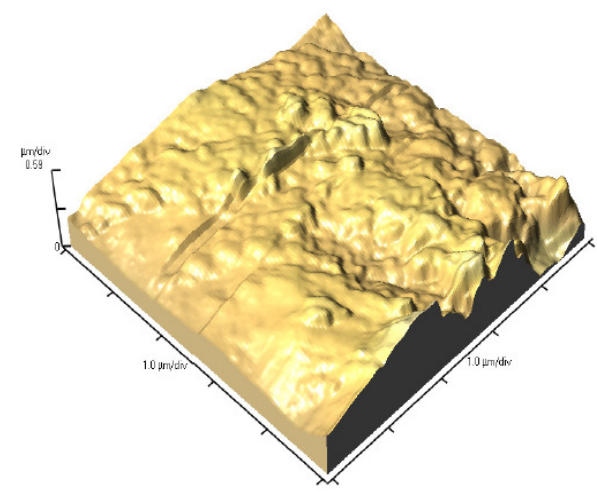

a)

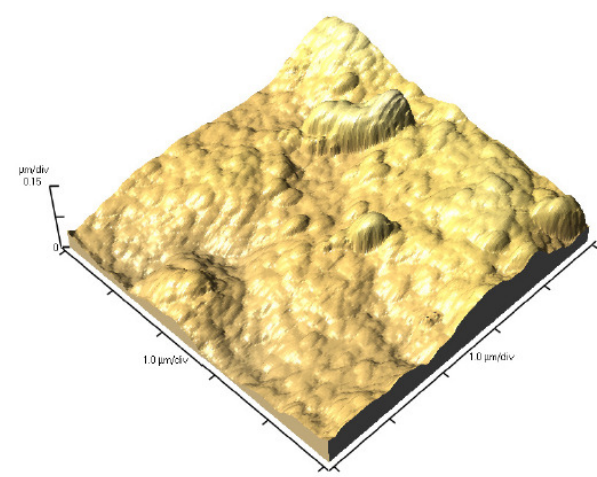

b)

Figure 8. Atomic force microscopy (AFM) images of mild steel in $0.5 \mathrm{M} \mathrm{H}_{2} \mathrm{SO}_{4}$ in (a) absence and (b) presence of $3 \mathrm{~g}$ of Musa paradisiaca extract.

\section{Conclusions}

1. The inhibition efficiency of Musa paradisiaca extract on corrosion of mild steel in $0.5 \mathrm{M} \mathrm{H}_{2} \mathrm{SO}_{4}$ solution increases on increasing of concentration of the extract and decreases with rise in temperature. Potentiodynamic polarization measurements show that Musa paradisiaca acts as a mixed type inhibitor.

2. Adsorption of inhibitor molecules of the extract on mild steel surface is found to obey Langmuir adsorption isotherm. The increase in the values of activation energies of the corrosion process in presence of the extract indicates that Musa paradisiaca extract creates a physical barrier to charge and mass transfer, leading to reduction in corrosion rate of mild steel in $0.5 \mathrm{M}$ $\mathrm{H}_{2} \mathrm{SO}_{4}$ solution. The negative values of $\Delta \mathrm{G}_{\text {ads }}^{\mathrm{o}}$ and $\Delta \mathrm{H}^{\mathrm{o}}$ ads highlight that the inhibition of corrosion of mild steel through adsorption is spontaneous and exothermic. Their values also reveal that both physical adsorption and chemisorption are involved in the adsorption process.

3. EIS measurement reveals that charge transfer resistance increases with increase in concentration of the extract, indicating that the inhibition increases with increase in concentrations.

4. SEM and AFM studies confirm that corrosion inhibition of mild steel in $0.5 \mathrm{M}$ $\mathrm{H}_{2} \mathrm{SO}_{4}$ is due to adsorption of the extract on it.

\section{Acknowledgement}

Authors are very thankful to University Grants Commission, India, for financial support for this research work. 


\section{References}

1. M.A. Quraishi, A. Singh, V.K. Singh, D.K. Yadav, A.K. Singh, Mater. Chem. Phys. 122 (2010) 114-122.

2. $\quad$ L.R. Chauhan, G. Gunasekaran, Corros. Sci. 49 (2007) 1143-1161.

3. J.C. Rocha, J.A.C.P. Gomes, E. D'Elia, Corros. Sci. 52 (2010) 2341-2348.

4. A. Ostavari, S.M. Hoseinieh, M. Peikari, S.R. Shadizadeh, S.J. Hashemi, Corros. Sci. 51 (2009)1935-1949.

5. H. Ashassi-Sorkhabi, E. Asghari, Electrochim. Acta 54 (2008) 1578-1583.

6. L.G. Trindade, R.S. Goncalves, Corros. Sci. 51 (2009) 1578-1583.

7. A.Y. El-Etre, Appl. Surf. Sci. 252 (2006) 8521-8525.

8. A.M. Abdel-Gaber, B.A. Abd-El-Nabey, M. Saadawy, I.M. Sidahmed, A.M. El- Zayady, "Corros. Sci. 48 (2006) 2765-2779.

9. E.E. Oguzie, Mater. Chem. Phys. 99 (2006) 441-446.

10. P.B. Raja, M.G. Sethuraman, Mater. Letter 62 (2008) 2977-2979.

11. P.C. Okafor, M.E. Ikpi, I.E. Uwah, E.E. Ebenso, U.J. Ekpe, S.A. Umoren, Corros. Sci. 50 (2008) 2310-2317.

12. A.M. Abdel-Gaber, B.A. Abd-El-Nabey, M.Saadawy, Corros. Sci. 51 (2009) 1038-1042.

13. K.O. Orubite, N.C. Oforka, Corros. Sci. 58 (2004) 1768-1772.

14. A.O. Odiongenyi, S.A. Odoemelam, N.O.Eddy, Port. Electrochim. Acta 27 (2009) 33-45.

15. S.K. Singh, A.N. Kesai, P.K. Rai, G. Watal, Ind. J. Clinical Biochem. 22 (2007) 48-52.

16. S. Ghareba, S. Omanovic, Corros. Sci. 52 (2010) 2104-2113.

17. C. Jeyaprabha, S. Sathiyanarayanan, K.L.N. Phani, G. Venkatachari, Appl. Surf. Sci. 252 (2005) 966-975.

18. A. Yurt, V. Butun, B. Duran, Mater. Chem. Phys. 105 (2007) 114-121.

19. A.K Satapathy, G. Gunasekaran, S.C. Sahoo, Kumar Amit, P.V. Rodrigue, Corros. Sci. 51 (2009) 2848-2856.

20. A.Y. El-Etre, Corros. Sci. 45 (2003) 2485-2495.

21. A.M. Fekry, Riham R. Mohamed, Electrochim. Acta 55 (2010) 1933-1939.

22. G. Achary, Y.A. Naik, S.V. Kumar, T.V. Venkatesha, B.S. Sherigara, Appl. Surf. Sci. 254 (2008) 5569-5573.

23. K. Babic-Samardzija, C. Lupu, N. Hackerman, A.R. Barron, J. Mater. Chem. 15 (2005) 1908-1916.

24. O.K. Abiola, A.O. James, Corros. Sci. 52 (2010) 661-664.

25. G. Moretti, F. Guidi, G. Grion, Corros. Sci. 46 (2004) 387-403.

26. Z. Tao, S. Zhang, W. Li, Ba. Hou, Ind. Eng. Chem. Res. 49 (2010) 25932599.

27. C. Liang, P.Wang, B.Wu an N. Huang, Mater. Corros. 62 (2011) 53-60.

28. S.M.A. Hosseini, M. Salari and M. Ghasemi, Mater. Corros. 60 (2009) 963-968.

29. M.A. Deyad, S.S. Abd El-Rehim, S.T. Keera, Colloids Surf. A: Physicochem. Eng. Asp. 348 (2009) 170-176. 
30. M.A. Migahed, A.M. Abdul-Raheim, A.M. Atta, W. Brostow, Mater. Chem. Phys. 121 (2010) 208-214.

31. D. Cetin, M.L. Aksu, Corros. Sci. 51 (2009) 1584-1588.

32. X. Sheng, Y.-P. Ting, S.O. Pehkaonen, Ind. Eng. Chem. Res. 46 (2007) 7117-7125. 